\title{
Apuntes sobre el neobarroco: de teorías y metalenguas
}

\author{
NOTES ON THE NEO-BAROQUE: OF THEORIES AND METALANGUAGE
}

Miguel Alvarado-Borgoño (miguel.alvarado@ucentral.cl) Facultad de Educación y Vicerrectoría Académica, Universidad Central de Chile (Santiago, Chile) ORCID: 0000-0002-1563-4108

\begin{abstract}
This article addresses the notion of Latin American baroque, linking its aesthetic and interpretive dimension with the cognitive, to develop a located epistemology in Latin America, consistent with its tradition and cultural history. This exercise requires a transdisciplinary effort, therefore this article takes the form of notes, in the context of a broader research program focusing on the contribution of the sociologist Pedro Morandé and writers Pablo Rokha and José Lezama Lima, in a transdisciplinary perspective that assumes theories of knowledge grounded in the identification of Baroque and Latin American appropriations as core of our cultural substrate and therefore epicenter of reflection on identity; developing emerging forms of writing grounded in a metalanguage that appeals to the neo-baroque as a foundation.
\end{abstract}

Key words: neobaroque, sociocultural theory, Latin America, scientific metalanguage, transdiscipline.

\section{Resumen}

En este artículo se aborda la noción de barroco latinoamericano, vinculando su dimensión estética e interpretativa con la cognoscitiva, para dar pistas en el desarrollo transdisciplinario de una forma de epistemología situada en Latinoamérica, coherente con su tradición e historia cultural. El ejercicio requiere un esfuerzo transdisciplinario, por ello el artículo toma la forma de apuntes, en el contexto de un programa de investigación más amplio, centrándose en un somero examen del aporte del sociólogo Pedro Morandé y de los escritores Pablo de Rokha y José Lezama Lima, ello en una perspectiva transdisciplinaria que asume teorías del conocimiento fundamentadas en la identificación del barroco y sus apropiaciones latinoamericanas, como médula de nuestro substrato cultural y por tanto, epicentro de la reflexión sobre la identidad, surgiendo un modo de desarrollar formas de escritura cimentadas en una metalengua que apela al neobarroco como fundamento.

Palabras clave: neobarroco, teoría sociocultural, Latinoamérica, metalenguas científicas, transdisciplina.

\section{Diapasón de la razón como tuerca sin hilo}

Dividir literatura y ciencias sociales para la comprensión de Latinoamérica hoy resulta un ejercicio arbitrario, ello porque antes de la fundamentación de la ciencia social establecida por los clásicos europeos como Max Weber o Augusto Comte, ya se forjaba en Latinoamérica una reflexión respecto de lo social, de forma coherente y sistemática, por parte de José Enrique Rodó, José Martí o Domingo Faustino Sarmiento, entre otros muchos ejemplos posibles. 
La llegada de las ciencias sociales como la sociología o la antropología en mucha medida intentó desconocer esta tradición de pensamiento, relegando al plano del diletantismo de cátedra, histórico o filosófico, a toda una tradición de pensamiento latinoamericano, muy emparentado con los desarrollos de las literaturas nacionales y de las formas de escritura periodísticas, teológicas e historiográficas. Durante la década de los sesenta y setenta estas ciencias, particularmente la sociología, produjo una cantidad de esfuerzos interpretativos de nivel altamente complejo y que aún poseen un valor académico y político: baste recordar las economías agrarias vinculadas a las reformas agrarias del periodo, la filosofía de la liberación, la teología de la liberación y el aporte que recibe de las ciencias sociales la pedagogía del oprimido y la teoría de la dependencia. Luego de este periodo, la década de los 80 son de una tremenda oscuridad debido a la persecución política a las ciencias sociales (con excepción de la economía de orientación teórica neoliberal) por parte de las dictaduras militares latinoamericanas que se entronizaron. Poco se pudo realizar más que en ONGs o en exilios diversos.

No obstante, específicamente en Chile, cuando aparece el libro del sociólogo Pedro Morandé (graduado de sociólogo en 1971) titulado: Cultura y Modernización en América Latina (1984), se marca un hito en el contexto de la alicaída y perseguida ciencia social producida en la dictadura chilena y latinoamericana; primero por su audacia interpretativa respecto del barroco, en una crítica abierta al neoliberalismo que suponía que el cambio social se generaba por las dinámicas de los mercados y que identitariamente se produciría la mutación cultural. El libro fue original, hace varias décadas ya, especialmente en sus usos interdisciplinarios de analogías que provenían del arte (siendo el autor fiel, quizás, a la hermenéutica de H. G. Gadamer o Paul Ricoeur) pero también fue irruptor y necesario, ya que ubicó a la sociología chilena en el marco de los procesos dictatoriales, es decir, fue un libro que se atrevió a soñar, pensando la sociedad, planteándose interpretativamente frente a la hegemonía de los economistas ideólogos de la dictadura pinochetista. Luego de la persecución de la Teoría de la Dependencia y de sus pensadores, este libro logra entender de alguna forma la crisis de nuestra modernización ilustrada, dándose la libertad de cuestionar la modernización misma, aún en el contexto de una inmensa opacidad como el vivido en la dictadura militar chilena.

Los procesos de construcción de la identidad latinoamericana en los últimos dos siglos han tenido como telón de fondo a la modernidad como pregunta y también como deseo, pero ello se ha constituido a través de un tránsito dialogante entre las bases conceptuales románticas e ilustradas redefinidas desde Latinoamérica. En el contexto de la formación de los Estados-Nación a lo largo del siglo XIX, las elites se vieron en la necesidad de articular el poder desde la cultura, apelando a la estética romántica como un eje propio de análisis crítico de la identidad social colonial y barroca, y pensando esta estética romántica como una filosofía del sentido capaz de constituirse en un referente metasocial secularizado, dador de sentido a los proyectos colectivos desarrollados a lo largo del siglo XX, aun así, el romanticismo no logró borrar la mancha barroca. De esta forma permanece desde la colonia un conflicto no resuelto con el Proyecto Ecuménico del Barroco como ideal estético y político del yo conquisto, asociado primero al Concilio de Trento y luego a distintos modos, tanto de encuentro entre lo barroco y lo indígena, como luego en un neobarroco secularizado.

De alguna manera en este artículo seguimos esa ruta, que hoy no es en sí novedad, ya que el cuestionamiento de la modernización latinoamericana en sí mismo es un área de interés que cuenta con un canon discursivo desde las ciencias sociales y la literatura. Nuestro intento es un poco más aventurado, deseamos vislumbrar los aportes del neobarroco en la construcción del conocimiento, particularmente de las ciencias humanas en una visión situada en suelo latinoamericano, ello en el contexto de una apuesta que centra al barroco en nuestra cultura. Este concepto puede ser asumido epistemológicamente de una 
manera transdisciplinaria, generando que la separación tipológica de los cánones científico social y el literario pierda su nitidez. Ese neobarroco produjo y produce incluso hoy sus más señeras obras en el ámbito de la literatura, por tanto el indagar en el barroco literario es no solo un esfuerzo legítimo para la ciencia literaria o la filología, sino para las ciencias sociales y específicamente para su epistemología, en tanto desde la literatura es posible encontrar claves de acceso a nuestra identidad, asunto ya desarrollado en nuestro medio por autores múltiples: desde los trabajos señeros de historia de las mentalidades de Mario Góngora respecto del barroco (quien, dicho sea de paso fue un tenaz opositor a los planteamientos de Morandé) y otros autores como Bernardo Subercaseaux, Leónidas Morales, Soledad Bianchi, Sonia Montecino, Jorge Guzmán, Grínor Rojo, entre otros y otras, cuyas obras no se ubican excluyentemente en el ámbito de la ciencia social o de la ciencia literaria. Son aportes que debieran ser más valorados por las ciencias sociales y humanas en plural y en las reflexiones epistemológicas en nuestro medio.

\section{El barroco como gozne y goce}

Desde un comienzo en el siglo XX, el barroquismo de Alejo Carpentier y luego el realismo mágico, definen la escritura de una forma original. En ella el lenguaje se conecta con el arte. Es allí donde el surrealismo se vincula diferenciándose del realismo mágico y donde el concepto de barroco asumido como una categoría lingüística adquiere en sí mismo, vida. El concepto de barroco definido desde su actualización semántica se constituye en un puente entre la experiencia vital, las racionalizaciones del mundo y la estética de la escritura.

Nuestra hipótesis consiste en sostener que en la literatura latinoamericana contemporánea se ha desarrollado un neobarroco durante el siglo XX, que tiene una correspondencia con el saber sociológico, con caminos tanto paralelos como complementarios. Hablamos no de transtextualidad o influencia directa, sino de conclusiones y formas teóricas y metalingüísticas que tres escribidores toman como punto de articulación de sus escrituras en Sudamérica. En este artículo damos someramente cuenta de las propuestas del sociólogo chileno Pedro Morandé, pero asumimos y no creemos que sea casual, que ello ya fue desarrollado con una gran profundidad por las metalenguas de diversos escritores y escritoras no cientistas sociales, de los cuales dos de sus representantes más señeros son Pablo de Rokha (nacido en Chile en 1894 y muerto en 1968) y José Lezama Lima nacido y muerto en La Habana (1910-1976). Asumimos el concepto de metalengua, influido por Walter Mignolo en su definición "hermeneutic and postcolonial aspects of the way texts speak of themselves" (2010:56) que utilizamos en este artículo (no como una categoría alternativa a la de epistemología), simplemente porque es un aporte de carácter operativo transdisciplinario, a nuestro entender tremendamente funcional: el concepto de metalengua como forma estética, en los textos canónicos o en textos asociados, dan cuenta de la reflexión de una comunidad hermenéutica creadora y receptora de textos.

Las metalenguas de estos autores dan cuenta de una paradoja que comprueba nuestra formulación de la radical importancia del neobarroco; son dos grandes escritores que, en la fundamentación metalingüística de sus obras, ya sea en sus ensayos teóricos o en sus producciones literarias mismas, generaron una robusta reflexión sobre Latinoamérica y su cultura. De Rokha y Lezama estuvieron separados por distancias geográficas y sociales (Chile y Cuba respectivamente), pero tienen un punto axial de coyuntura al mirar nuestros estilos de vida y formas culturales, desde la incidencia, permanencia y reformulación del barroco, al asumirlo como el fundamento psicocultural de nuestra identidad, ya sea en la generación de sincretismo o en la yuxtaposición e incluso en el solapamiento de formas culturales. 


\section{Morandé y su tesis del barroco}

Para este autor se trata de re-mirar nuestra política y nuestras formas de desarrollo dependiente y periférico desde la reflexión sociológica ampliada en la transdisciplina y así abrirse a lo que luego Morandé definiría como una modernidad barroca. No se trata solo de una clave literaria o sociológica, sino que es un punto de mira transdisciplinario desde la literatura y hacia las ciencias humanas, lo que asumimos como una forma válida a nivel del desarrollo de una epistemología de las ciencias sociales específicamente situada en Latinoamérica.

Desde la sociología, Pedro Morandé afirma que la identidad cultural latinoamericana, como fenómeno social y estético, se ha constituido históricamente desde el barroco. Según Morandé, la primera fuente de la tradición popular latinoamericana se origina en la matriz precolombina, la que posee como cultura arcaica, un centro que el autor define como Dramático-Sacrificial y un carácter cosmocéntrico, expresado en la esfera de lo ritual. El drama y el sacrificio serían elementos sustanciales en el curso histórico de nuestras culturas. Los procesos históricos y la vivencia de la cotidianeidad estarían marcados por cuotas de dolor en el sentido social del término, los que configurarían una sucesión interminable de quiebres y rupturas en un devenir histórico propio, generando un tipo de comprensión de la historia que se mueve más en el ámbito de la escatología que de la cronología. El tiempo escatológico propio de lo cosmocéntrico nos refiere a una historicidad atemporal, al tiempo de los dioses, imposible de ser medido dentro de los parámetros de la temporalidad moderna. Sin embargo, la historia de este tiempo puede ser contada desde el rito, lugar donde subyace este relato. Este último, al ser una reactualización del mito escatológico, revive $y$, por lo tanto, recuenta la historia en una sucesión cíclica infinita, de la cual el barroco reinterpretado en Latinoamérica, es su expresión axial.

\section{Oficio de dar nombres, oficio de pensar: de las tesis del barroco a una analogización estética}

Cuando el poeta Pablo de Rokha acuñó el término Suramerika para referirse a nuestros lares o el cubano José Lezama Lima hablaba de un Paradiso que no era en sí el paraíso, pero en algún sentido oscuro lo era; daban cuenta de un intento, por una parte, de generar neologismos culturalmente situados, que son del mismo modo una floritura barroca y un intento de nombrar de otra manera el escenario latinoamericano, situándose en la especificidad de su experiencia histórica y geográfica para así generar unas formas retóricas polisémicas, que lejos de crear ambigüedad, intentaban un tipo de pensamiento situado; se tratará de un estilo de escribir que, sin quererlo, será prolongado por escrituras practicadas desde otras formas de comprensión, como lo son el post-colonialismo, la teología de la liberación o la filosofía de la liberación. No se trata de una búsqueda original, en tanto empeño, sino de una gran literatura y del mismo modo, del ejercicio del oficio del pensamiento, que en De Rokha y en Lezama exceden los límites incluso de la literatura misma, para ofrecérsenos como un modo de pensamiento vivo y vigente, por ejemplo, frente a las corrientes posmodernistas o a las apologéticas del neoliberalismo.

El neobarroco es anterior y más totalizador transdisciplinariamente que el realismo mágico. Cabe señalar que el término realismo mágico apareció en las críticas a las artes plásticas y solo después se extendió a la literatura. Lo utilizó el crítico alemán Franz Ruth en 1925 para caracterizar a un grupo de pintores postexpresionistas y luego fue reemplazada por el término nueva objetividad. A pesar de este cambio, el realismo mágico sirvió para definir una tendencia en la narrativa hispanoamericana desarrollada entre 1950 a 1970. El neobarroco es sencillamente algo más rotundo: una forma transdisciplinaria de comprender a Latinoamérica. 
Hemos querido en estas notas utilizar desde el campo literario dos ejemplos polares; en primer lugar, por la calidad indudable de las obras de José Lezama Lima y Pablo de Rokha. Lezama elabora un estilo que recoge el barroco de Góngora y Cervantes, junto a la lengua y la imaginería religiosa cubana y asume su obra metalingüísticamente como una obra neo barroca: incide poderosamente en otros autores cubanos, de los más importantes son Severo Sarduy y Reinaldo Arenas. Pablo de Rokha vive su soledad en el estilo hablando localmente, pero ya definiendo metalingüísticamente lo que rimbombantemente llamó el barroco popular americano.

Había mucho que unía a Lezama y De Rokha, como también mucho que los diferenciaba, pero hay un aspecto en el que son analécticamente homólogos, es decir, comparados transculturalmente desde la legitimidad del otro. Son dos formas de pensar poetizante de indudable valor lírico, pero que de todas maneras no deben ser olvidadas en tanto pensamiento en sí mismas. Las metalenguas de estos dos autores son dos maneras de pensar y actuar desde la influencia barroca europea y, por tanto, dos maneras de reflexión que, aunque apelan al logos socrático, no están capturadas en la suposición e identidad metafísica entre realidad y razón.

\section{Un paganismo epistemológico}

Se ha dicho que no existe una filosofía y en general unas ciencias humanas latinoamericanas verdaderamente situadas, también que el pensamiento latinoamericano está inalterablemente colonizado y su papel es resignificar lo ya dicho bajo el sayo de la periferia, borde a veces fructífero, a veces poco original y tedioso. Por el contrario, pensamos que desde la llegada del barroco en la conquista de Latinoamérica hispano lusitana, se comienzan a edificar formas de pensamiento en los márgenes, en la sustitución, en la fusión o en la contraposición de formas culturales. Por ello la confluencia de este sociólogo de fines del siglo XX con estos dos escritores de mediados de siglo, nacidos en los albores del siglo $\mathrm{XX}$, no es casual, sino parte de los ríos subterráneos que son estilo de vida, cultura, pensamiento y espiritualidad sudamericanos.

Si el barroco fue el proyecto cultural con el cual la corona española intentó generar en Latinoamérica una ecúmene universal de pueblos, bajo la egida paulista de la comunión en la diversidad, la teología del barroco europeo de inspiración y su matriz eminentemente jesuítica, no son parte del modelo teológico y cultural de cristiandad de las formas de pensamiento propias de la teología de Pablo de Tarso, sino que responden a un modelo de cristiandad más que de cristianismo, modelo imperial acuñado por Constantino y definido desde la filosofía y la teología propias del Concilio de Trento y del pensamiento que dio lugar a la Escuela de Salamanca, a partir de la influencia magistral de Francisco de Vitoria, y del Derecho Indiano, todas ellas formas que dieron paradojalmente el andamiaje ético al más grande genocidio en la historia humana, esto es la conquista y colonización de América, pero también dieron lugar a la práctica concreta de una visión de la persona humana con un alma inmortal que no era, por ejemplo, la del imperio inglés.

Severo Sarduy definió el neobarroco como la perla irregular. Nosotros libremente lo interpretamos como el modo específico en que aún hoy la exacerbación de la forma, propia del barroco, se expresa en un orden del desbarajuste, sin que ello sea un juego de palabras, es decir, se expresa en una lógica que no identifica lo racional con lo real, sino que vive en el intento de la representación y de la representación de la representación. Para teóricos de la literatura y la cultura, como Ángel Rama o de la sociología como Pedro Morandé, Latinoamérica ha dado lugar a un barroquismo esencial, su lógica es la que va desde el ritual a la palabra y allí hacia lo audiovisual, en una interacción prolífica y que, para el logos colonizador, puede parecer contradictoria. 
Para comprender el neobarroco y, por lo tanto, comprender la metalengua de Lezama Lima y De Rokha, por no decir sus filosofías latinoamericanas, definidas desde sus producciones literarias debemos, ante nada, ser capaces de entender algo que al parecer la teología católica no pudo asumir, desde el documento del Concilio Vaticano II Evangelii Nuntianddi, hasta los documentos del episcopado católico latinoamericano de Puebla a Aparecida: para esta teología, el sincretismo es siempre una expresión de una semilla del verbo, por lo tanto el encuentro entre dos o más formas culturales dentro de las cuales se encuentra el cristianismo, darán lugar a una nueva forma, ello muy emparentado con la teoría de los círculos culturales del difusionismo alemán.

Debemos afirmar categóricamente que para entender el neobarroco de Lezama y de De Rokha, nos resulta mucho más atingente pensar desde los ensayos y la obra de José María Arguedas, ello representa una necesidad interpretativa y no un enciclopedismo diletante literario: José María Arguedas en sus ensayos sobre los pueblos de la Sierra Peruana, pero especialmente en la propia metalengua de sus novelas, no creía en el sincretismo como producto inevitable; no olvidemos que Arguedas fue antropólogo y escritor, y que no sabemos que fue antes y que después, pero nos demostró categóricamente que frente a una relación de opresión, las formas culturales indígenas no son ni necesariamente sincretizables con las formas occidentales, ni tampoco necesariamente resultan en una armonía de lo heterogéneo. Por el contrario, en nuestra lectura de Arguedas, vemos siempre la confrontación, aquello que el antropólogo peruano Manuel Marzal ha denominado la "yuxtaposición" (2004:41) o el pensador argentino Néstor García Canclini ha entendido de manera acertada, aunque desde otro horizonte teórico y transdiciplinario, como "hibridación" (2004:60).

Desde este marco comprensivo, apelamos a una transdisciplina que integra literatura, antropología, historia, teología y sociología, para decirnos que en los artefactos culturales neobarrocos no será necesariamente la armonía de la síntesis sincrética la que primará, sino algo muy distinto: la tensión permanente entre formas culturales hegemónicas, logocéntricas y europeas y formas culturales ancestrales latinoamericanas, que lejos de necesariamente sintetizarse, viven una permanente pugna, lo cual da lugar a distintos tipos de violencias, tanto físicas como simbólicas. Ni De Rokha ni Lezama apelaron a un barroquismo siempre sincrético, al contrario de Morandé, quien parte del concepto de sincretismo para explicar el barroco; he aquí un punto poco estudiado, pero por lo pronto en estos apuntes deseamos recalcar la importancia de asumir al neobarroco como una epistemología de resistencia a la síntesis forzada o dicho de otra manera, asumiremos al neobarroco como un paganismo epistemológico, que disfraza un modo de conocer cuyas raíces, muchas veces solapadas, son anteriores a la llegada del barroco a nuestros lares.

Pareciera ser que, en el contrapunto, en la producción de José Lezama Lima y Pablo De Rokha, se parte de la premisa que el temple de ánimo de la poesía y la prosa de Pablo De Rokha sería la de la grandilocuencia, aunque como corrigiera De Rokha al crítico Mario Ferrero y que ha sido resaltado de manera más contemporánea por la nueva crítica literaria chilena, no se trató de una escritura grandilocuente, sino de gran elocuencia.

Por su parte, José Lezama Lima aparece siempre como un neobarroco que a la manera de Lope de Vega o de su venerado Francisco Quevedo hizo uso de las sierpes que los clásicos barrocos les entregaba y por tanto de la literatura clásica, greco-latina, para construir un todo impoluto que pareciera lejos de lo latinoamericano. Pensamos por el contrario, que ambos autores constituyen una literatura y una metalengua literaria que podríamos definir como de la pendencia, son hijos de una cólera que no es propia de un sincretismo consumado, de un amalgamamiento pulido, sus obras son la expresión no de una 
síntesis inconclusa, sino de la especificidad de una forma que, en palabras de Paul de Mann, sería una retórica que contiene a la poética. Son ambas del mismo modo, una lírica que intenta ser ante todo elocutiva, pero que por sobre todo, representa siempre una falta, como diría Derrida, esta falta es la carencia de la posibilidad misma de la comunicación, particularmente en términos transculturales, su pendencia, es la pendencia que genera la yuxtaposición, es la expresión del autor textual que intenta expresar la imposibilidad de comunicar lo específico, de lo latinoamericano, pero también es una forma inmensamente respetable de expresar la inevitabilidad de la yuxtaposición.

Si asumimos solo que De Rokha y Lezama son parte del neobarroco latinoamericano y cerramos la interpretación que nos aportan de nuestra Latinoamérica, simplemente estamos escapando a un intento de definir más profundamente ese neobarroco, desde una síntesis que no es síntesis, sino perpetuación de la yuxtaposición que es enfrentamiento y lucha permanente; es la lucha interior del poeta por expresar un mundo con las estrechas palabras de Castilla la vieja, pero también es expresión de una Latinoamérica, que permanentemente reaviva sus conflictos, no solo por la separación entre elite y masa, sino por el modo en que las especificidades quedan detenidas a la espera de la síntesis, en una expectación que es escatológica, pero que también es una farsa política.

Severo Sarduy, en sus textos sobre la India, afirmaba que le generaba una tremenda paz y del mismo modo, un curioso arraigo el visitar los lugares sagrados indios y mirar a los habitantes de India, debido a que eran inmensamente similares a Cuba, a la que no podía regresar por razones políticas. Cuando leemos esta afirmación, nos parece en una primera recepción, una suerte de guiño barroco, a la tremenda complejidad y heterogeneidad india, pero en la lectura que aquí hacemos del propio Sarduy, podemos afirmar que a lo que se refería era más bien, a la gigantesca división entre castas, lenguas, religiones, cosmovisiones políticas y razas que hacen de la India un tipo de alteridad casi incomprensible para los latinoamericanos, pero que en el fondo, es expresión de la misma incomunicabilidad en la que queda la Latinoamérica colonizada. Vivir la ilusión del diálogo intercultural es vivir la ilusión, entre otras facetas, de un diálogo fundado en el imperialismo inglés en India, o en el remoto imperialismo hispano-lusitano en Latinoamérica. Pero Pablo De Rokha y Lezama Lima tenían razón, el barroco latinoamericano y su propia escritura neobarroca son expresiones de un algo que no es ni la Raza de Bronce de Alcides Arguedas o de la Raza Cósmica de José Vasconcelos; más bien es la soledad metaforizada por Octavio Paz, o García Márquez, que no deviene en una contemplación pasiva, sino en el conflicto latente y por momentos sorpresivo.

\section{La lira y la cimitarra / La oz y el martillo}

No se trata en estas líneas de establecer con precisión cuáles fueron las metalenguas de De Rokha o Lezama, no desde una émica parcial, ni desde un hermenéutica más amplia, ello involucraría una comparación intercultural que se opondría a lo transcultural; más que comparar nos intenta reconocer el surco unificante que posibilitó un modo de comprender, un algo que es poesía pero que va más allá de la poesía y allí justamente entra lo transdisciplinario; el hilo delgado que une pero que, a la manera de una red de telaraña atrapa, eso es el barroco, asumido en términos de Sarduy como un a perla irregular, es decir con una luz negra en palabras de Lezama, un algo que es del mismo modo exacerbación de la forma, desborde, voluptuosidad y riqueza, que expresión de una situación de dominación, de menoscabo, de descredito, es lo vulgar, lo que es heterogéneo y que no se reconoce hilvanado y es también una persistencia histórica, una forma de gozar y de morir; es el modo en que en Latinoamérica la yuxtaposición, lejos del sincretismo y la síntesis ha mantenido su forma en resistencia, íntima a veces y violenta en otras, desde la queja implícita en el rito de la religiosidad popular, hasta la exacerbación necrófila de la masacre. 
Las victorias son las victorias de los muertos y las derrotas son un retirarse lentamente para reaparecer en el momento y lugar menos indicado, menos supuesto, en el lugar del coro barroco, el lugar de la política de los acuerdos, el lugar del tratado de libre comercio, para destruir la ilusión de orden social o estético.

Se trata de un barroco tan ladino e inoportuno, que debería ya permitirnos asumir, por lo contumaz y reiterado, que es una manera de sufrir y de gozar, que hace posible la sobrevivencia de un sistema étnico social. El barroco latinoamericano es, de cierta manera, un invento jesuita que se constituyó en un mecanismo pedagógico y seductivo de la colonización. Hoy es resistencia, rezongo y caos, frente a las órdenes y especialmente frente a las suposiciones de un rumbo de la historia. En Pablo de Rokha hay una poética que es un modo de pensamiento popular, paradojalmente escribió para las masas y no fue leído por ellas, pero al escribir asumió un destino: "comprendo y admiro a los líderes" (De Rokha 1998:88).

Si de Rokha y Lezama quisieron adoptar la forma de profetas, no lo lograron a la manera de un Jeremías y sus certidumbres, sino a la manera de Job, llenos de dudas y al final repletos del fracaso, desilusión en Lezama del obeso olvidado, decepción en el caso de De Rokha de un hombre muy ilustrado, muy conspicuo, pero suicida en el fracaso, en la certidumbre interna del desengaño.

\section{¿Qué es una luz negra?}

En la disyuntiva y contrapunto se erige la luz negra. Nada más antitético que Pablo De Rokha y José Lezama, en sus personalidades hay algo radicalmente opuesto, no hubo contacto entre ambos y si lo hubiera habido no sabemos si hubiese llegado a buen puerto. Uno posiblemente homosexual, el otro homofóbico, uno católico santero, el otro materialista histórico, uno cubano, el otro chileno, uno cantor de la cultura popular, el otro defensor de la cultura cubana como totalidad.

Pero en ambos existe un acercamiento a lo popular: en Lezama en la santería, en la fe, pero por sobre todo en el amor a La Habana, en ese tremendo amor también a Cuba, lo que le impidió irse, cuando pudo hacerlo, de la isla. En de Rokha en la convicción de que solo sería fiel a lo fundamental moralmente desde el marxismo-leninismo y era leal con respecto al Partido Comunista de Chile, aunque lo expulsaron de él.

El punto de articulación de ambos es su fe inquebrantable en un algo que está ausente, una fe en una forma de metafísica anti-ilustrada, pero está presente en la luz negra que representan, ese algo es la coherencia de lo simultáneamente contrapuesto, en sus estéticas de la yuxtaposición: la luz negra es la de la coherente incoherencia.

Es el juego quebrado y lineal del mismo modo, en creer y no creer en oscurecer y dar brillo. Hay una cultura superior en ambos autores. De Rokha se autodefinió directamente como el Cíclope de Eurípides y Lezama se blandió como el valedor de 400 siglos de cultura cubana.

Cuando Descartes antepone el lenguaje ante la ofensiva de la experiencia, no hace más que demostrar lo que los jesuitas ya sabían: que nuestros ojos te mienten, pero el establecimiento de relaciones causa efecto en el pensamiento ya sea en un proceso inductivo o deductivo implica algo más complejo, la apelación metafísica al ceteris paribus, es decir a la creencia mágica de que todo se mantiene constante excepto aquello que se encuentra en análisis: falacia de la falacia, mito racional logocéntrico. Lezama no entendía así las cosas, no creía en un mundo estático histórico y se circunscribe a la política de las miradas que no temen a la sombra y al hechizo. 
El barroco por el contrario asume desde esa exacerbación que parece tan desordenada un modo de comprensión: entender que en el definir de los hechos, cada cosa es causa y efecto de otra, y que dialéctica y analécticamente, la causa y el efecto son asunto de quien describe: describe escribiendo en este caso en De Rokha y Lezama es una poética de la mirada que fija el ojo en aquello que asume como preponderante por un acto volitivo, pero también por la especificidad de las circunstancias históricas donde aquello se produce.

Dios, el cogito, el ser, la especificidad histórica, la casualidad, no son más que la metafísica hechizada de la mirada respecto de la cual el barroco opta por causas y efectos haciendo gala de su arbitrariedad y convirtiendo esa arbitrariedad en el epicentro del artefacto histórico. El barroco está en la historia, comprende la historia, pero la mirada lírica barroca debe estar fuera de la historia, fuera de la circunstancia, pero dentro de la mirada y de la forma de mirar, hasta dar con la perla irregular, perla que es siempre negra porque encarna la disyuntiva.

\section{Ejercicios para un intento de definición del barroco: de las estrofas para la definición de la perla irregular}

Resulta un ejercicio absurdo, pero por sobre todo improductivo, el intentar definir el barroco desde la lógica estricta de la ciencia literaria, si entendemos a esta como una forma de comprensión del fenómeno literario a partir de asumir que toda la teoría del conocimiento asociada al barroco es una gran diatriba en contra, primero del cartesianismo y luego del proyecto de la ilustración y prontamente es políticamente un modo de contravenir las formas de dominación propias del mercantilismo y del capitalismo, que son proporcionadas por el discurso filosófico de la modernidad. Parece obvio decirlo, pero debemos decirlo: ni el barroco ni ninguna forma de neobarroco son ni pueden ser epistémicamente modernas, por lo tanto, asumir erradamente, por ejemplo, que el neobarroco de Carpentier es solo una versión latinoamericana del surrealismo, es tanto eurocentrismo como discapacidad interpretativa.

Definir una perla irregular, desde los cánones de la simetría, resulta un profundo contrasentido; la ciencia literaria que desde el romanticismo alemán se asentó en la historia cultural y luego contemporáneamente, trató de emular los progresos cartesianos de la lingüística; no puede ser el instrumento que nos permitirá definir aquello que es exactamente lo contrario.

Pensamos que el principal problema, al definir la forma barroca que nos preocupa, es el neobarroco latinoamericano, un producto entendido como una epistemología con proyecciones icónicas, es decir, como una teoría del conocimiento, que en vuelo rasante tendrá efectos meta-estéticos y producirá por lo tanto, artefactos estéticos heterodoxos, no obstante el barroco, por sobre todo, es una praxis, pero no una praxis intuicionista, sino que por el contrario, es un hacer que posee su fundamento y del mismo modo, va erigiendo sus prácticas, una dialéctica entre mente y acción, que permite la operación analéctica del equiparamiento transcultural. El Barroco específicamente latinoamericano es acción y reacción, es decir, es un actuar de manera reactiva frente a situaciones y movimientos culturales de los países centrales, es reaccionario en un sentido revolucionario.

\section{Lezama, el egregio barroco}

Dos grandes autores contemporáneos cubanos como Severo Sarduy y Reinaldo Arenas, teniendo y reconociendo una deuda ineludible e hidalgamente asumida por estos, confesaron de distinta manera el temor reverencial que les provocaba acercarse a Lezama, simplemente por el miedo que les generaba acercarse a una persona tan culta. Quien tuvo más contacto con él fue Reinaldo Arenas y en sus memorias, 
escritas en Estados Unidos antes de morir de VIH, reconoce una rara virtud de Lezama, al menos rara según Arenas en el contexto sudamericano y esto es la absoluta honestidad intelectual de la que hacía gala Lezama incluso en el plano más íntimo, asumida la homosexualidad de Lezama y de Sarduy, este le apoya, dejándole primeramente en claro que no tiene ningún interés sexual en su persona, sino simplemente desea apoyar un valor literario que necesita de complementos formativos, de lecturas, en definitiva de un padre polimorfo que guíe los pasos sin definir la senda.

Hay otro fragmento de estas memorias que no deja de emocionar y es cuando cuenta el último periodo de la vida de Lezama, rodeado por el hambre, la miseria y por sobre todo, la marginación, momento posterior a la Carta de Fidel Castro a los intelectuales y del Caso Padilla y por ello, al intento atroz de limitar la cultura cubana: Arenas dice que Lezama escribía simplemente porque era su oficio, su vocación, el sentido de su existencia, aunque tuviera la certeza de que lo que escribiera sería raudamente destruido por la seguridad del Estado. Más allá del anti-castrismo absoluto de Arenas, esto constituye el testimonio del ejercicio de esa honestidad que nunca abandonó a Lezama.

Lezama, más allá de la conciencia que tuviera de su valor literario, se consideraba a sí mismo como depositario de cuatrocientos años de cultura cubana, lo que a decir de Martín Heidegger, aunque probablemente Lezama no lo supiera, es autoconferirse el rol de guardián ineluctable del mito. Su vida es un escribir sin pausa ni pena, pero siempre escribir, a decir de Rafael Alberti me queda la palabra y la palabra permaneció hasta el último momento de su vida, en que murió obeso y olvidado. Al momento de morir, el periódico oficial Granma, publicó la noticia de modo casi irónico, en la que en cuatro líneas se hablaba de la muerte del poeta, como si se tratara de un poeta menor, ello hace juego con la falta de interés que suscitó la publicación de una de las obras maestras de la lengua española del siglo XX: Paradiso, gran libro inclasificable y sofisticadamente barroco; solamente Juan Goytizolo y Julio Cortázar hicieron mención pública en Cuba a esta novela, su castigo fue el silencio, pero no se logró el amedrentamiento o al menos no se logró el objetivo perseguido por esencia, detener la escritura.

Vemos algo de un sentimiento de culpa colectivo en el día de la diversidad sexual celebrado hoy en Cuba y en la publicación incansable, con los escasos recursos que se cuenta de las obras completas de Lezama. ¿En qué consistía el barroquismo de José Lezama Lima? Pensamos que a nivel lírico ello se expresaba en el juego con el neologismo que hace al lector romper los cánones clásicos de una lectura comprensiva, hay en su obra más alusión a la mitología clásica grecolatina que a la fe del autor, por ejemplo en los Orishas, pero es el neologismo que va abriendo a otros neologismos lo que le permite destruir el lenguaje y rehacerlo. Su escritura no es una escritura de la certidumbre ilustrada, sino más bien una escritura fundamentada en un conjunto de tropos que dan lugar siempre a esbozos axiológicos. Pero esta axiología es la de una retórica fundamentada en los tropos metafóricos: es decir, no intenta fundamentar un sistema de valores, sino que da cuenta del valor como un punto metafórico, se trata de un intercambio de atributos que superan el nivel de los tropos retóricos; del mismo modo, ese valor expresado en el tropos se sustenta en una metalengua sensual, material y corpórea: en el cuestionario incluido en la edición de Paradiso de Cintio Vitier. Esta pregunta a Lezama, en qué medida su expresión literaria está determinada por las percepciones sensoriales, el oído, la vista, el olfato, etc.

Valiéndose de su prestigio Lezama, consigue burlar la vigilancia de los censores y publicar, en 1966, su obra máxima, Paradiso, cuyos célebres capítulos VII y VIII, desbordante de referencias homosexuales, hirió bastante la recatada virilidad socialista, empeñada en extirpar el demonio de los cuerpos. Hoy es incansablemente emulado o cuasi plagiado por los escritores cubanos, especialmente los de la diáspora. Uno de sus muchos libros se tituló La cantidad hechizada y justamente esta frase es el oxímoron que afirma 
para luego refutar, pero que en sí contiene, no una acepción metafísica en cuanto esbozar un argumento sistemático, sino que en la contradicción radicalizada, unida a la retórica de la aceptación, se aproxima al ser; lo esencial de la poética de Lezama no es su epistemología, sino su ontología como metafísica del ser, como búsqueda de un fundamento de aquello que anticipadamente se sabe que no puede ser comprendido, pero Lezama intenta que ese algo al menos sea nombrado. Ello no significa ni sincretización ni mestizaje; ni en la concepción de su propia obra, en su metalengua por lo tanto, no apela a una síntesis inevitable, ni en su forma de ver el arte en general. Es así como dijo: "Por muy localista que sea una reflexión de un fenómeno puntual: "Una realidad étnica mestiza, no tiene nada que ver con una expresión mestiza. Entre nosotros han existido mestizos que han intentado expresarse dentro de los cánones del parnasianismo, y gran parte de la poesía afrocubana, en cambio, es de poetas de raza blanca. Se ve que una cosa es el mestizaje y otra abogar por una expresión mestiza. Una expresión mestiza es un eclecticismo artístico que no podrá existir jamás" (Lezama 1977:51).

\section{Pablo de Rokha. El huaso de Licantén se inmola}

Cuando en el año 1968 el poeta Pablo De Rokha se suicida poniéndose en la boca y disparando el inmenso revolver que le había regalado el presidente de México, Lázaro Cárdenas, por haber cabalgado junto a él la cabalgata de los revolucionarios (a lomo de caballo, en montura de palo), nuestro autor no hizo más que concluir una tragedia personal asociada a la muerte de dos de sus hijos y por sobre todo a la muerte de su musa y esposa, la genial poeta Winett De Rokha; nada lo consolaba de la muerte de la amada, en una manera casi romántica decimonónica de asumir el amor heterosexual. Como dijo el periodista Tito Mundt, su amigo entrañable, Pablo De Rokha fue el viudo más viudo de Chile.

Hay un hecho dramático, que del mismo modo es una anécdota: existía en Chile un diario con carácter de pasquín de izquierda de orientación bastante poco académica y lleno de groserías, llamado El Clarín, donde pocas frases poéticas salían de sus páginas, pero al momento de morir el poeta Pablo De Rokha, en letras rojas anunció su muerte diciendo: El huaso de Licantén de cara al infinito.

¿Qué hace que un periódico acostumbrado a la diatriba violenta, a la exageración y por sobre todo, a los galimatías retóricos, tuviese tamaña fineza espiritual como para afirmar que el huaso (campesino) de Licantén (una aldea) se hallaba de cara al infinito? Existen muchas maneras distintas de anunciar que un hombre ha muerto, también de anunciar que un hombre se ha suicidado, pero hay muy pocas maneras de decirlo, que sean tan respetuosas, tan líricas, tan enfáticas. Si hay un punto en el cual se unen De Rokha y Lezama, es en la coherencia ética de su escritura y en una soledad plenamente asumida, lo que da lugar a una exacerbación de la forma, que se origina superficialmente en la influencia del romanticismo y del modernismo en la primera época de Pablo De Rokha, pero luego, en la creación de un neologismo El barroco popular americano.

Pablo De Rokha, por sí mismo y siendo un hombre de una extremada cultura logocéntrica y eurocéntrica, descubre que el fundamento, es decir el ser de la cultura latinoamericana, está en su barroquismo. De Rokha no solo fue barroco en su escritura, sino que apeló permanentemente a que el estilo de masas que intentaba construir era un estilo barroco, en tanto exacerbación de la forma, muchas veces poco cuidado en la redacción, pero sobre todo de gran declamación, dijo alguna vez: "cuando nos equivocamos nos equivocamos a lo grande, como se equivocan los pueblos" (De Rokha 1969:45). Resulta paradójico que el estilo de masas de De Rokha lo redujera a lo que él denominaba como la plaza de provincia, no obstante, la vida va acompañada con la poesía. Hay en De Rokha un descuido casi despectivo respecto de las normas del estilo e incluso en relación a las normas de redacción de la lengua castellana, no intenta generar un 
purismo poético, sino hacer de su poesía una analogía de la historia latinoamericana; de Rokha quiso ser el gran cantor de los movimientos sociales, pero fue un gran teórico de las formas culturales identitarias latinoamericana.

El barroco popular americano es el fundamento ontológico del arte sudamericano para Pablo De Rokha, pero también es un modo de estar en el mundo. Quizás la obra en que mejor expresa como entiende al ser humano de América Latina sea su libro Escrituras de Raimundo Contreras, que anticipa en el estilo y la innovación en más de una década a la obra Finnigan Wake de James Joyce. Pensamos que más allá de la adhesión estética o incluso del estudio de la ciencia literaria, explorar la metalengua de la obra de Pablo De Rokha puede resultar un instrumento heurístico y transdisciplinario que nos permita entender las diferentes manifestaciones de la identidad Suramericana.

El barroco caribeño descrito por Lezama, caracterizado en su mezcla entre neologismos, figuras mitológicas grecolatinas y formas culturales sincréticas afroamericanas y el barroco popular americano de la Suramérica de Pablo De Rokha, son dos claves axiales de interpretación, que van más allá de la elucidación.

\section{Conclusión}

En la Latinoamérica de hoy lo interdisciplinario aparece como la forma de un significante flotante, se crean y se financian doctorados interdisciplinarios, por parte de los Estados Nacionales, ello con el fin de ensanchar las formas de interpretación que provienen de las ciencias humanas. Ello es en sí loable, pero en numerosas ocasiones ha resultado que la mentada interdisciplina es solamente un modo de acceder a los objetos de análisis desde distintas miradas disciplinarias, asunto que no es ni remotamente novedoso, especialmente desde el nacimiento de ciencias como la semiótica o la bioquímica. Pero el gran error consiste en suponer la existencia de un objeto fijo que es analizado desde miradas múltiples; ese objeto no existe sino en la mente de los "investigadores interdisciplinarios latinoamericanos". Proponemos el concepto de transdisciplina como un modo de acceso que atraviesa las disciplinas y no se posiciona particularmente en ninguna, sino que construye analécticamente el problema a investigar, apelando a otro proceso: la transculturalidad; la comparación transcultural supone la equiparación de categorías culturales en el reconocimiento de sus diferencias y sus similitudes, para que el camino sea la obra, es decir, para que no exista un objeto objetivo de conocimiento, sino que sean seres humanos, que en el intento de comprensión de lo humano, vayan reconociendo nudos problemáticos y vayan internándose heurísticamente en ello.

En este camino transdisciplinario y transcultural, la comprensión que aporta la poesía es de medular importancia, porque es la única capaz de generar los tropos necesarios que den nombre, tanto a las nuevas preguntas que se van presentando respecto de lo humano, como también a las nuevas respuestas, en un proceso analéctico transcultural y trandisciplinario, que no homologa fenómenos culturales distintos, como tampoco fija a priori problemáticas, sino que va hermenéuticamente construyendo su pregunta sobre las bases de las relaciones capciosas entre lenguaje, pensamiento y realidad.

La poesía es capciosa, porque contiene todos los tropos posibles y la poesía neobarroca de José Lezama Lima, y Pablo De Rokha, son grandes monumentos metódicos que las ciencias humanas recién hoy comienzan a reconocer, desde el examen del valor del barroco jesuítico tridentino, hasta el neobarroco que nunca será surrealismo, pero si será, por sobre todo vida. 
Asumir las escrituras de Lezama Lima y de Pablo de Rokha, junto a la compleja metalengua que contienen, no solo tiene sentido para la ciencia literaria sino que nos lleva por el camino de la transdisciplina, a valorar los aportes heurísticos contemporáneos de sus concretas formas de mirar y realizar la literatura. Si hemos marcado sus diferencias debemos marcar sus coincidencias, pero ello dará lugar a un modo de acceder a lo latinoamericano desde este pensar poetizante, pero en una mirada útil no solo para la literatura sino ahora desde la interpretación cultural: interpretación que del mismo modo intenta ser situada, como también que intenta ser transcultural. La exacerbación de la forma no es un exceso, sino un modo de expresión que colectiva o individualmente da un sentido a la soledad del estilo, así también su modo de asumir el barroco tridentino es yuxtapuesto y por tanto tensionado. Los signos europeos se redefinen elaborando una literatura y por tanto unos artefactos culturales que son propios de Latinoamérica.

Sus literaturas superan o al menos van más allá, tanto del orden cartesiano e incluso del logocentrismo occidental. La razón tradicional suele ser un obstáculo y se admite la contradicción, lo yuxtapuesto, la forma oblicua, no como un accidente, sino como una manera de expresar nuestra identidad.

Son obras en definitiva que tienen voluntad de representar, pero los órdenes discursivos de su tiempo las marginan. No se puede aceptar tanta verdad, es la verdad de no ser una literatura occidental, sino de ser una poética del extremo oriente de oriente, a decir de Enrique Dussel, en un mundo redondo. Por tanto, las relaciones causa-efecto o la diferencia entre realidad y mito son descartadas para dar una lógica al texto. Es la otra lógica lo que asombra.

El milagro del aporte de Pedro Morandé, realizado en plena dictadura militar chilena, consiste en asumir la verdad de lo barroco como corriente cultural de la colonización en un fundamento dinámico de lo que hoy somos como latinoamericanos. Su postura que orientó mucho del pensamiento católico latinoamericano de finales del siglo XX, asume el sincretismo como base de nuestra identidad; disentimos de ello, pero valoramos el llevar una categoría estética al ámbito de la interpretación sociológica, volviendo de alguna manera a la ensayística decimonónica, que fue olvidada, como fue olvidado el barroco mismo y que hoy recuperamos como apelación a la autenticidad intelectual, no original sino fundante del pensamiento tanto en la elite como en la masa. En este ensayo hemos apelado a la elite, buscando modos de aproximación a un algo que solo es reconocido por esa misma elite en las formas culturales populares. Se supera así de alguna sinuosa manera el colonial modo logocentrado de entendernos que ve en el mundo occidental europeo y en sus proyecciones el único, el fundamento de todo lo pensable. Lezama y De Rokha conocieron profundamente la cultura grecolatina y la literatura del siglo XX, pero su pensamiento fue Ladino y barrocamente no logocentrado: un algo que Morandé, De Rokha y Lezama entrevieron y que aún no es plenamente asumido.

\section{Financiamiento}

Artículo redactado bajo el proyecto Fondecyt Regular №1151112.

\section{Bibliografía}

De Rokha, P. 1998. Epopeya de las comidas y las bebidas de Chile: canto del macho anciano. Santiago: Universitaria.

De Rokha, P. 1969. Mis grandes poemas. Antología. Santiago: Nacimiento. 
García Canclini, N. 2004. Ante la sociedad del conocimiento: últimos desafíos de las políticas culturales. Telos. Cuadernos de Comunicación, Tecnología y Sociedad 61:58-61.

https://telos.fundaciontelefonica.com/telos/articulocuaderno.asp@idarticulo=4\&rev=61.htm

Lezama Lima, J. 1977. Obras completas. México: Aguilar.

Marzal, M. 2004. Identidades culturales y religiosas en América Latina ante la globalización. Diàlegs: revista d'estudis polítics $i$ socials 7(24): 35-54.

Mignolo, W.2010. Desobediencia epistémica. Retórica de la modernidad, lógica de la colonialidad y gramática de la descolonialidad. Buenos Aires: Ediciones del Signo.

Morandé, P. 1984. Cultura y modernización en América Latina. Santiago: Universidad Católica de Chile.

Recibido el 2 Ago 2016

Aceptado el 17 Oct 2016 